\title{
The promoter polymorphism of NFKB1 gene contributes to susceptibility of ischemic stroke in Korean population
}

\author{
Su Kang Kim ${ }^{1, *}$, Hyang Mi Jang ${ }^{2, *}$, Dae-Young Kim ${ }^{3, *}$ \\ 'Department of Biomedical Laboratory Science, Catholic Kwandong University, Gangneung, Korea \\ 2Department of Basic Nursing Science, School of Nursing, Kyungdong University, Wonju, Korea \\ ${ }^{3}$ Department of Sports Healthcare, College of Humanities \& Social Sciences, Inje University, Gimhae, Korea
}

The progression of ischemic stroke is associated with inflammatory response, in which the nuclear factor kappa B subunit 1 (NFKB1) plays an important role. The aim of present study was to determine whether promoter single nucleotide polymorphism (SNP) in the NFKB1 gene was contributed to susceptibility of ischemic stroke. One hundred twenty-one Korean adult patients with ischemic stroke $(65.7 \pm 12.1$ years in age) and 291 Korean healthy controls $(63.0 \pm 9.3$ years in age) were recruited. We genotyped a promoter SNP (rs11940017, -1727, C/T) of $N F K B 1$ gene using direct sequencing in 121 Korean ischemic stroke patients and 291 control subjects. The T/C genotype of rs 11940017 SNP in the codominant model (vs. the T/T genotype) (odds ratio [OR], 0.38; 95\% confidence interval [CI], 0.15-0.92; $P=0.032$ ) and the genotype containing $C$ allele ( $T / C$ and $C / C$ ) in the dominant model (vs. the $T / T$ genotype) (OR, 0.33; 95\% Cl, 0.14-0.81; $P=0.0068$ ) were associated with a decreased risk of ischemic stroke. The frequency of $C$ allele was decreased in ischemic stroke patients, compared with control subjects (OR, 0.31; 95\% Cl, 0.13-0.74; $P=0.008$ ). These results suggest that the promoter SNP (rs11940017, -1727, C/T) of NFKB1 gene may affect ischemic stroke susceptibility in Korean population.

Keywords: Stroke, Nuclear factor kappa B subunit 1, Gene, Polymorphism

\section{INTRODUCTION}

Ischemic stroke terms a condition caused by the occlusion of a blood vessel supplying the brain (Ceulemans et al., 2010) and represents more than $80 \%$ of all stroke cases (Candelario-Jalil, 2009; Durukan and Tatlisumak, 2007). Recent evidence indicates that inflammation plays an important role in ischemic stroke (McColl et al., 2009). Chronic inflammatory response is associated with stroke and neurodegenerative diseases (Frank-Cannon et al., 2009; Lucas et al., 2006). Moreover, after cerebral ischemia, the death of ischemic neurons and the release of necrotic cell debris trigger a robust inflammatory reaction (Lelekov-Boissard et al., 2009; Simi et al., 2007; Wang et al., 2007). Many therapeutic trials for inflammation-associated brain injuries have been applied (Cho et al., 2015; Han et al., 2016; Shin et al., 2016).

Nuclear factor-kappaB (NFKB) is a major transcription regula- tor of immune response, apoptosis, and cell-growth control genes (Karban et al., 2004). It plays a central role in modulation of inflammation (Orozco et al., 2005). The NFKB names a variety of transcription factors that are homo- or hetero-dimers of p $50, \mathrm{p} 52$, p65, RelB, and c-Rel (Pereira and Oakley, 2008; Perkins, 2007). Of those subunits, the p50, encoded by NFKB1 gene, is known to have both pro- and anti-inflammatory properties. The p50/p65 heterodimer stimulates transcription of pro-inflammatory cytokines, whereas the p50/p50 homodimer induces transcription of anti-inflammatory cytokine (Cao et al., 2006; Ghosh et al., 1998; Pereira and Oakley, 2008; Perkins, 2007). Thus, the expression of NFKB1 gene may be related to balancing the inflammatory response (Pereira and Oakley, 2008).

Considering the known relevance of inflammation in ischemic stroke, a possible role of NFKB1 gene polymorphisms on susceptibility to ischemic stroke cannot be ruled out. We analyzed single
${ }^{*}$ Corresponding author: Dae-Young Kim (D) https://orcid.org/0000-0002-4662-4463 College of Humanities \& Social Sciences, Inje University, 197 Inje-ro, Gimhae 50834, Korea

Tel: +82- 55-320-3171, Fax: +82-55-320-3545, E-mail: cdps21@inje.ac.kr

${ }^{\#} \mathrm{Su}$ Kang Kim and Hyang Mi Jang contributed equally to this study as co-first authors. Received: October 22, 2018 / Accepted: November 17, 2018
This is an Open Access article distributed under the terms of the Creative Commons Attribution Non-Commercial License (http://creativecommons.org/licenses/by-nc/4.0/) which permits unrestricted non-commercial use, distribution, and reproduction in any medium, provided the original work is properly cited. 
nucleotide polymorphism (SNP) in the promoter of NFKB1 gene and investigated the genetic association between susceptibility of ischemic stroke and NFKB1 gene in Korean population.

\section{MATERIALS AND METHODS}

\section{Subjects}

One hundred twenty-one Korean adult patients with ischemic stroke $(65.7 \pm 12.1$ years in age, mean \pm standard deviation) and 291 Korean healthy controls $(63.0 \pm 9.3$ years $)$ were enrolled for this study. The patient group was comprised of 68 males and 53 females. Each patient was diagnosed using the cranial computed tomography, magnetic resonance imaging (MRI), or angiography. The patients were classified by well-trained two physicians into clinical phenotypes according to the results of the National Institutes of Health Stroke Survey (NIHSS) and the Modified Barthel Index (MBI), respectively. The neurological deficit on admission was measured using the NIHSS. The outcome at hospital discharge was assessed using the MBI. Patients with trauma, vascular malformations, brain tumors, and congenital brain disorders were excluded. The control group was comprised of 152 men and 139 women. Healthy control subjects were selected among participants examined in a general health check-up program. Participants with transient ischemic attack, ischemic heart diseases, and

Table 1. Demographic findings of the study subjects

\begin{tabular}{lcc}
\hline Variable & Ischemic stroke $(n=12)$ & Control $(n=291)$ \\
\hline $\begin{array}{l}\text { Age (yr) } \\
\text { Gender }\end{array}$ & $65.7 \pm 12.1$ & $63.0 \pm 9.3$ \\
Male & $68(56.2)$ & $152(52.2)$ \\
Female & $53(43.8)$ & $139(47.8)$ \\
NIHSS (score) & & \\
$<6$ & 56 & - \\
$\geq 6$ & 57 & - \\
MBI (score) & & - \\
$<60$ & 71 & - \\
$\geq 60$ & 25 & \\
\hline
\end{tabular}

Values are presented as mean \pm standard deviation or number (\%) unless otherwise indicated.

NIHSS, National Institutes of Health Stroke Survey; MBI, Modified Barthel Index. other atherosclerotic diseases were excluded. Age and gender of the control group was matched with those of the patient group. A summary of demographic findings of ischemic stroke patients and control subjects were provided in Table 1. Written informed consent was obtained from each patient or the legal guardian. The protocol for this study was approved by the ethics review committee of the Medical Research Institute, School of Medicine, Kyung Hee University (Seoul, Korea).

\section{SNP selection and genotyping}

We searched SNPs of NFKB1 gene in the coding and promoter regions. Relevant information was obtained from the National Center for Biotechnology Information SNP database (http://www.ncbi. nlm.nih.gov/SNP; dbSNP BUILD 131). There were 16 SNPs with a heterozygosity $>0.1$ in the coding and promoter regions of NFKB1. Of those SNPs, all of 6 SNPs in the coding region and 9 of 10 SNPs in the promoter region were excluded because of monomorphic genotype. Consequently, rs11940017 (-1727, C/T) in the promoter region was selected.

Peripheral blood samples were collected from each subject and then stored in a $-20^{\circ} \mathrm{C}$ refrigerator. Genomic DNA was extracted from the blood samples using a QIAamp DNA mini kit (QIAGEN, Valencia, CA, USA). SNP genotyping was conducted by direct sequencing (MACROGEN, Seoul, Korea). Polymerase chain reactions (PCRs) were performed with specific primer for rs11940017 (Table 2). The PCR products were sequenced using an ABI PRISM 3730XL DNA Analyzer (PE Applied Biosystems Inc., Foster City, CA, USA). Sequence data were analyzed using SeqManII software (DNASTAR Inc., Madison, WI, USA).

\section{Statistical analysis}

The SNPStats (Biostatistics and Bioinformatics Unit, Barcelona, Spain) was used to analyze genetic data. Hardy-Weinberg equilibrium (HWE) was assessed. The effects of SNP genotypes were analyzed using 4 models; codominant (codominant 1: T/T [reference] vs. $\mathrm{T} / \mathrm{C}$; codominant 2 : $\mathrm{T} / \mathrm{T}$ vs. $\mathrm{C} / \mathrm{C}$ ), dominant (T/T [reference] vs. $\mathrm{T} / \mathrm{C}+\mathrm{C} / \mathrm{C})$, recessive $(\mathrm{T} / \mathrm{T}+\mathrm{T} / \mathrm{C}$ [reference] vs. $\mathrm{C} / \mathrm{C})$, and $\log -$ additive (T/T vs. T/C vs. C/C) models (Yang, 2017a; Yang, 2017b). Logistic regression analyses were used to calculate the odds ratios

Table 2. Sequence of primer used for the SNP

\begin{tabular}{|c|c|c|c|c|}
\hline SNP & & Sequence $\left(5^{\prime}-3^{\prime}\right)$ & Product size (bp) & Annealing temperature $\left({ }^{\circ} \mathrm{C}\right)$ \\
\hline \multirow[t]{2}{*}{ rs11940017 (-1727, C/T) } & Sense & САТСTССТСТСТСТGCСAAGTT & 391 & 59 \\
\hline & Antisense & GAACCTGGGGGGAGGGGTTACT & - & - \\
\hline
\end{tabular}

SNP, single nucleotide polymorphism. 
Table 3. Genotype and allele frequencies of NFKB1 polymorphism in control subjects and ischemic stroke patients

\begin{tabular}{|c|c|c|c|c|c|c|}
\hline SNP & Genotype \& allele & Control & Ischemic stroke & Model & OR (95\% Cl) & $P$-value \\
\hline \multirow[t]{10}{*}{ rs11940017 promoter $(-1727, C / T)$} & Genotype & & & & & \\
\hline & $\mathrm{T} / \mathrm{T}$ & $251(86.2)$ & $115(95.0)$ & Codominant 1 & $0.38(0.15-0.92)$ & $0.032^{*}$ \\
\hline & $\mathrm{T} / \mathrm{C}$ & $36(12.4)$ & $6(5.0)$ & Codominant 2 & $0.00(0.00-N A)$ & NA \\
\hline & $\mathrm{C} / \mathrm{C}$ & $4(1.4)$ & $0(0)$ & Dominant & $0.33(0.14-0.81)$ & $0.0068^{*}$ \\
\hline & & & & Recessive & 0.00 (0.00-NA) & NA \\
\hline & & & & Log-additive & $0.38(0.16-0.94)$ & $0.021^{*}$ \\
\hline & & & & & $0.34(0.15-0.80)$ & $0.0043^{*}$ \\
\hline & Allele & & & & & \\
\hline & $\mathrm{T}$ & $538(92.4)$ & $236(97.5)$ & & Reference & \\
\hline & C & $44(7.6)$ & $6(2.5)$ & & $0.31(0.13-0.74)$ & $0.008^{*}$ \\
\hline
\end{tabular}

NFKB1, nuclear factor of kappa light polypeptide gene enhancer in B-cells 1; SNP, single nucleotide polymorphism; OR, odds ratio; Cl, confidence interval; NA, not applicable. $P$-values were from logistic regression analyses with codominant, dominant, recessive and log-additive models.

Codominant 1, T/T genotype (reference) vs. T/C genotype; Codominant 2, T/T genotype (reference) vs. C/C genotype; Dominant, T/T genotype (reference) vs. T/C+C/C genotypes; Recessive, T/T+T/C genotypes (reference) vs. C/C genotype; Log-additive, $T / T$ genotype vs. T/C genotype vs. C/C genotype.

${ }^{*} P<0.05$, statistically significant.

(ORs), 95\% confidence intervals (CIs), and $P$-values with controlling age and gender as covariables. Allele frequencies were compared by Pearson chi-square test. Statistical analyses were performed using SPSS ver. 17.0 (SPSS Inc., Chicago, IL, USA). The significance level for statistical test was set at $P$-value of $<0.05$.

\section{RESULTS}

Genotype distribution of rs11940017 SNP (-1727, C/T) of NFKB1 gene in the control group was consistent with the HWE $(P>0.05$; data not shown). The genotyping data revealed that rs11940017 SNP (-1727, C/T) was associated with the susceptibility of ischemic stroke (Table 3). The frequencies of $\mathrm{T} / \mathrm{T}, \mathrm{T} / \mathrm{C}$, and $\mathrm{C} / \mathrm{C}$ genotypes were $86.2 \%, 12.4 \%$, and $1.4 \%$, respectively in the control group, and $95.0 \%, 5.0 \%$, and $0 \%$ in the ischemic stroke group, respectively. The $\mathrm{T} / \mathrm{C}$ genotype was associated with a decreased risk of ischemic stroke, compared to the $\mathrm{T} / \mathrm{T}$ genotype (codominant model; OR, 0.38; 95\% CI, 0.15-0.92; $P=0.032$ ). In the analysis using the dominant model, the genotype containing $\mathrm{C}$ allele ( $\mathrm{T} / \mathrm{C}$ and $\mathrm{C} / \mathrm{C}$ ) was associated with a decreased risk of ischemic stroke, compared to the T/T genotype (OR, 0.33; $95 \%$ CI, 0.14-0.81; $P=0.0068$ ). The frequencies of $\mathrm{T}$ and $\mathrm{C}$ alleles were $92.4 \%$ and $7.6 \%$, respectively in the control group, and $97.5 \%$ and $2.5 \%$, respectively in the ischemic stroke group (OR, $0.31 ; 95 \% \mathrm{CI}, 0.13-0.74 ; P=0.008)$. These data suggest that the promoter SNP (rs11940017, -1727, C/T) of NFKB1 gene was associated with susceptibility of ischemic stroke.

\section{DISCUSSION}

The relation between peripheral immune cells and the brain has been suggested (Park et al., 2016). In this study, we observed that the NFKB1 promoter polymorphism, rs11940017 (-1727, C/T), was associated with ischemic stroke. We particularly found that the $\mathrm{C}$ allele of rs11940017 might contribute to a decreased risk of ischemic stroke in Korean population.

The NFKB1 gene encodes a $105 \mathrm{kD}$ non-DNA-binding protein (p105) of nuclear factor-kappa B (NF-kB), which can undergo cotranslational processing to produce a 50-kD DNA-binding protein (p50) (Karban et al., 2004). NF- $\kappa B$ names a number of different transcription factors that are homo- or hetero-dimers of p50, p52, p65, RelB and c-Rel (Pereira and Oakley, 2008; Perkins, 2007). The major form of NF-kB is a heterodimer of the p50 and p65 subunits (Chen et al., 1999). The p50 subunit, encoded by NFKB1 gene, has both pro- and anti-inflammatory properties: As part of the $\mathrm{p} 50 / \mathrm{p} 65$ heterodimer, the $\mathrm{p} 50$ controls transcription of pro-inflammatory cytokines such as tissue necrosis factor and interleukin-1 $\beta$ (Perkins, 2007). In the p50/p50 homodimer, it has anti-inflammatory properties by repressing transcription of pro-inflammatory cytokines and by stimulating transcription of anti-inflammatory cytokine (Cao et al., 2006; Ghosh et al., 1998; Pereira and Oakley, 2008). Thus, the relative abundance of $\mathrm{p} 50 / \mathrm{p} 65$ heterodimers and $\mathrm{p} 50$ homodimers may determine the magnitude of inflammation by balancing the pro-inflammatory and anti-inflammatory responses (Pereira and Oakley, 2008). If an altered NFKB1 transcription would lead to a decreased $\mathrm{p} 50$ synthesis, fewer $\mathrm{p} 50$ homodimers may be formed and 
a stronger activation of transcription of pro-inflammatory genes can be induced (Borm et al., 2005). Given this role in inflammatory processes, polymorphisms in the promoter of NFKB1 may modulate the susceptibility to ischemic stroke because inflammation is a risk factor for ischemic stroke.

Some clinical studies investigated a relation between a functional promoter polymorphism of NFKB1 gene and immune-mediated diseases including ulcerative colitis (Borm et al., 2005; Karban et al., 2004), acute respiratory distress syndrome (Adamzik et al., 2007; Bajwa et al., 2011), cervical cancer, dilated cardiomyopathy (Zhou et al., 2009), and coronary heart disease (Vogel et al., 2011). However, the genetic association between NFKB1 polymorphisms and ischemic stroke has not been published in the literature, even though the NF- $\kappa \mathrm{B}$ pathway is suggested as one of mechanisms of ischemic stroke (Martín-Ventura et al., 2004; Nurmi et al., 2004). Thus, we searched SNPs in the promoter and coding regions of NFKB1 gene and selected a promoter polymorphism, rs11940017. In our data, the $C$ allele was the minor allele of rs11940017 and was related to a lower risk of ischemic stroke (OR, $0.31 ; 95 \% \mathrm{CI}$, $0.13-0.74)$. The genotype containing $C$ allele was further decreased in patients with ischemic stroke. We presumed that the relative frequency of the $\mathrm{T}$ and $\mathrm{C}$ alleles of rs11940017 might be able to alter the activity of NFKB1 transcription. We expect, in the further study, to simultaneously investigate the genotype frequencies and the NF- $\mathrm{KB}$ activity between ischemic stroke patients and control subjects.

In conclusion, we found statistically significant association between rs11940017 SNP of NFKB1 gene and the susceptibility to ischemic stroke in Korean population. Here in this study, we report a relation between NFKB1 gene and ischemic stroke.

\section{CONFLICT OF INTEREST}

No potential conflict of interest relevant to this article was reported.

\section{REFERENCES}

Adamzik M, Frey UH, Rieman K, Sixt S, Beiderlinden M, Siffert W, Peters J. Insertion/deletion polymorphism in the promoter of NFKB1 influences severity but not mortality of acute respiratory distress syndrome. Intensive Care Med 2007;33:1199-1203.

Bajwa EK, Cremer PC, Gong MN, Zhai R, Su L, Thompson BT, Christiani DC. An NFKB1 promoter insertion/deletion polymorphism influences risk and outcome in acute respiratory distress syndrome among Cau- casians. PLoS One 2011;6:e19469.

Borm ME, van Bodegraven AA, Mulder CJ, Kraal G, Bouma G. A NFKB1 promoter polymorphism is involved in susceptibility to ulcerative colitis. Int J Immunogenet 2005;32:401-405.

Candelario-Jalil E. Injury and repair mechanisms in ischemic stroke: considerations for the development of novel neurotherapeutics. Curr Opin Investig Drugs 2009;10:644-654.

Cao S, Zhang X, Edwards JP, Mosser DM. NF-кB1 (p50) homodimers differentially regulate pro- and anti-inflammatory cytokines in macrophages. J Biol Chem 2006;281:26041-26050.

Ceulemans AG, Zgavc T, Kooijman R, Hachimi-Idrissi S, Sarre S, Michotte $Y$. The dual role of the neuroinflammatory response after ischemic stroke: modulatory effects of hypothermia. J Neuroinflammation 2010; 7:74.

Chen F, Castranova V, Shi X, Demers LM. New insights into the role of nuclear factor-kappaB, a ubiquitous transcription factor in the initiation of diseases. Clin Chem 1999;45:7-17.

Cho YS, Shin MS, Ko IG, Kim SE, Kim CJ, Sung YH, Yoon HS, Lee BJ. Ulinastatin inhibits cerebral ischemia-induced apoptosis in the hippocampus of gerbils. Mol Med Rep 2015;12:1796-1802.

Durukan A, Tatlisumak T. Acute ischemic stroke: overview of major experimental rodent models, pathophysiology, and therapy of focal cerebral ischemia. Pharmacol Biochem Behav 2007;87:179-197.

Frank-Cannon TC, Alto LT, McAlpine FE, Tansey MG. Does neuroinflammation fan the flame in neurodegenerative diseases? Mol Neurodegener 2009;4:47.

Ghosh S, May MJ, Kopp EB. NF-кB and Rel proteins: evolutionarily conserved mediators of immune responses. Annu Rev Immunol 1998; 16:225-260.

Han MH, Lee EH, Koh SH. Current opinion on the role of neurogenesis in the therapeutic strategies for Alzheimer disease, Parkinson disease, and ischemic stroke; considering neuronal voiding function. Int Neurourol J 2016;20:276-287.

Karban AS, Okazaki T, Panhuysen CI, Gallegos T, Potter JJ, Bailey-Wilson JE, Silverberg MS, Duerr RH, Cho JH, Gregersen PK, Wu Y, Achkar JP, Dassopoulos T, Mezey E, Bayless TM, Nouvet FJ, Brant SR. Functional annotation of a novel NFKB1 promoter polymorphism that increases risk for ulcerative colitis. Hum Mol Genet 2004;13:35-45.

Lelekov-Boissard T, Chapuisat G, Boissel JP, Grenier E, Dronne MA. Exploration of beneficial and deleterious effects of inflammation in stroke: dynamics of inflammation cells. Philos Trans A Math Phys Eng Sci 2009;367:4699-4716.

Lucas SM, Rothwell NJ, Gibson RM. The role of inflammation in CNS injury and disease. Br J Pharmacol 2006;147 Suppl 1:S232-240.

Martín-Ventura JL, Blanco-Colio LM, Muñoz-García B, Gómez-Hernán- 
$\operatorname{dez}$ A, Arribas A, Ortega L, Tuñón J, Egido J. NF-kappaB activation and Fas ligand overexpression in blood and plaques of patients with carotid atherosclerosis: potential implication in plaque instability. Stroke 2004;35:458-463.

McColl BW, Allan SM, Rothwell NJ. Systemic infection, inflammation and acute ischemic stroke. Neuroscience 2009;158:1049-1061.

Nurmi A, Lindsberg PJ, Koistinaho M, Zhang W, Juettler E, KarjalainenLindsberg ML, Weih F, Frank N, Schwaninger M, Koistinaho J. Nuclear factor-kappaB contributes to infarction after permanent focal ischemia. Stroke 2004;35:987-991.

Orozco G, Sánchez E, Collado MD, López-Nevot MA, Paco L, García A, Jiménez-Alonso J, Martín J. Analysis of the functional NFKB1 promoter polymorphism in rheumatoid arthritis and systemic lupus erythematosus. Tissue Antigens 2005;65:183-186.

Park HS, Park MJ, Kwon MS. Central nervous system-peripheral immune system dialogue in neurological disorders: possible application of neuroimmunology in urology. Int Neurourol J 2016;20(Suppl 1):S8-14.

Pereira SG, Oakley F. Nuclear factor-kappaB1: regulation and function. Int J Biochem Cell Biol 2008;40:1425-1430.

Perkins ND. Integrating cell-signalling pathways with NF-kappaB and IKK function. Nat Rev Mol Cell Biol 2007;8:49-62.
Shin MS, Park HK, Kim TW, Ji ES, Lee JM, Choi HS, Kim MY, Kim YP. Neuroprotective effects of bone marrow stromal cell transplantation in combination with treadmill exercise following traumatic brain injury. Int Neurourol J 2016;20(Suppl 1):S49-56.

Simi A, Tsakiri N, Wang P, Rothwell NJ. Interleukin-1 and inflammatory neurodegeneration. Biochem Soc Trans 2007;35(Pt 5):1122-1126.

Vogel U, Jensen MK, Due KM, Rimm EB, Wallin H, Nielsen MR, Pedersen AP, Tjønneland A, Overvad K. The NFKB1 ATTG ins/del polymorphism and risk of coronary heart disease in three independent populations. Atherosclerosis 2011;219:200-204.

Wang Q, Tang XN, Yenari MA. The inflammatory response in stroke. J Neuroimmunol 2007;184:53-68.

Yang SA. Association study between ZFHX3 gene polymorphisms and obesity in Korean population. J Exerc Rehabil 2017a;13:491-494.

Yang SA. Lack of association between glutathione s-transferase mu 1 (GSTM1) gene polymorphisms and obesity. J Exerc Rehabil 2017b;13: 608-612.

Zhou B, Rao L, Peng Y, Wang Y, Li Y, Gao L, Chen Y, Xue H, Song Y, Liao $\mathrm{M}$, Zhang L. Functional polymorphism of the NFKB1 gene promoter is related to the risk of dilated cardiomyopathy. BMC Med Genet 2009;10:47. 